\title{
Immunofluorescent Localization of PGK-1 and PGK-2 Isozymes within Specific Cells of the Mouse Testis
}

\author{
JAMES M. KRAMER \\ Department of Human Genetics, University of Michigan Medical School, Ann Arbor, Michigan 48109
}

Received December 22, 1980; accepted in revised form April 20, 1981

\begin{abstract}
The ubiquitous isozyme of phosphoglycerate kinase, PGK-1, and the testis-specific isozyme, PGK-2, have been localized to specific cells of the testis by indirect immunofluorescence on Bouin's fixed testis sections. The earliest cell of the spermatogenic series in which PGK-2 is detectable by immunofluorescence is the Stage 12 spermatid. The intensity of fluorescence increases as the spermatids progress to later stages and is strong in both released spermatids and their residual bodies. PGK-2 is not detectable in premeiotic germinal cells or somatic cells of the testis. Specific fluorescence for PGK-1 is localized to the somatic cells of the testis: the interstitial and Sertoli cells.
\end{abstract}

\section{INTRODUCTION}

Two isozymic forms of phosphoglycerate kinase (PGK) (EC 2.7.2.3) have been identified in mammals. The activity of the PGK-1 isozyme is detected in all tissues and the gene has been shown to be X-linked in man (Chen et al., 1971; Meera Khan et al., 1971), kangaroo (Cooper et al., 1971), and mouse (Kozak et al., 1973; Nielsen and Chapman, 1977). The PGK-2 isozyme is found only in the testes and sperm of most mammals (VandeBerg et al., 1973) and has been shown to be autosomally inherited in the kangaroo (VandeBerg et al., 1980 ) and the mouse (VandeBerg et al., 1976). In the mouse, $P g k-2$ is linked to the $H-2$ complex on Chromosome 17 (Eicher et al., 1978; VandeBerg and Klein, 1978).

VandeBerg et al. (1976) studied the appearance of PGK-2 in developing mouse testis homogenates by starch gel electrophoresis. PGK-2 activity was first detectable at 22 days of age, which corresponds to the first appearance of early stage spermatids. ${ }^{1}$ Maximal levels of PGK-2 were attained by approximately 60 days of age. PGK-2 accounts for all or nearly all of the PGK activity in mature sperm (VandeBerg et al., 1973; Chen et al., 1976). These data suggest that PGK-2 is an isozyme specifically activated during spermatogenesis and may thus be valuable for studying gene expression during spermatogenesis.

In order to determine which cells of the testis contain PGK-1 and/or PGK-2 I have carried out indirect immunofluorescence with antisera which are isozyme specific. I report here that PGK-2 is localized exclusively in postmeiotic cells of the testis, exhibiting very intense

\footnotetext{
1 The differentiation of spermatids has been divided into 16 stages (1-16) (Oakberg, 1956). In a more general sense we refer to early (18), middle (9-13), and late (14-16) stage spermatids.
}

immunofluorescence in late stage spermatids. PGK-1 is present at much lower levels and is associated primarily with interstitial and Sertoli cells.

\section{MATERIALS AND METHODS}

Animals. CD-1 mice, purchased from Charles River or random bred from their stock, were used for all experiments. They were maintained under a 14-hr-light, 10-hr-dark cycle with $3: 1$, pine:cedar bedding.

Antisera. Antisera prepared by injecting rabbits with either purified PGK-1 or PGK-2 were kindly provided by Dr. C. -Y. Lee (Pegoraro et al., 1978; Lee et al., 1980). Normal rabbit serum was obtained from nonimmunized animals. All sera were fractionated by three ammonium sulfate precipitations ( $33 \%$ saturation), resuspended in borate-buffered saline $\mathrm{pH} 8.0$, and stored at $-70^{\circ} \mathrm{C}$ in small aliquots.

Preparation of PGK-2 for serum absorption. Partially purified PGK-2 was prepared essentially as described by Lee et al. (1980). Testes from 25 mice were homogenized in 4 vol of $10 \mathrm{mM}$ Tris- $\mathrm{HCl} \mathrm{pH} \mathrm{8.0,1} \mathrm{mM}$ dithiothreitol, $1 \mathrm{~m} M$ EDTA, centrifuged at $100,000 \mathrm{~g}$ for $1 \mathrm{hr}$, and the supernatant was loaded onto a DEAEcellulose column $(1.6 \times 20 \mathrm{~cm})$ equilibrated with the same buffer. PGK-1 was eluted by washing with 2.5 column vol of buffer and then PGK-2 was eluted with a linear $10-100 \mathrm{~m} M \mathrm{NaCl}$ gradient. Fractions containing PGK-2 activity were pooled and vacuum concentrated. This procedure completely separates PGK-1 from PGK2 and results in a 20- to 30-fold purification of PGK-2.

Serum absorptions. Liver homogenates or partially purified PGK-2 were coupled to $\mathrm{CNBr}$-activated Sepharose (Pharmacia). The anti-PGK-2 serum was absorbed on liver and the anti-PGK-1 serum was absorbed on PGK-2 to remove cross-reactivity (Lee et al., 1980). 
All sera were also massively absorbed on mouse spleen cells (equal volume of sera to packed cells).

Tissue preparations. Fixation of testes was performed with either Bouin's, 3.7\% formaldehyde in PBS, 95\% ethanol, or several concentrations of glutaraldehyde. Bouin's was found to be optimal for the preservation of cellular morphology and immunofluorescence and was used for all reported studies. Testes were fixed overnight, dehydrated, and imbedded in paraffin at $62^{\circ} \mathrm{C}$. Sections were cut at $5 \mu \mathrm{m}$ and affixed to albumincoated slides.

Mouse myoblasts grown on coverslips were fixed overnight in Bouin's and subsequently treated as were the testes sections.

Indirect immunofluorescence technique. Sections were cleared, rehydrated, and soaked in Dulbecco's phosphate-buffered saline (PBS) for $15 \mathrm{~min}$ and in 10\% newborn calf serum (GIBCO) in PBS for an additional 15 min. Excess fluid was blotted from the slides and sera $(10-15 \mu \mathrm{l})$ was applied to the sections. Slides were incubated in a moist box at $32^{\circ} \mathrm{C}$ for $30 \mathrm{~min}$, washed for $15 \mathrm{~min}$ in three changes of PBS followed by $5 \mathrm{~min}$ in $10 \%$ serum-PBS. Fluorescein isothiocyanate (FITC)conjugated goat anti-rabbit IgG (Cappel Labs), diluted $1: 100$ in $10 \%$ serum, was applied to the sections and the slides were incubated as above. The slides were washed for 20-30 min in four or five changes of PBS and coverslips were mounted with 9:1, glycerol:PBS.

All sera were serially diluted with $10 \%$ calf serumPBS to obtain maximum specific fluorescence. There were no changes in specific fluorescence upon dilution except that a stronger diffuse background developed at the lowest dilutions. Routinely, anti-PGK-1, anti-PGK2 , and normal rabbit serum were used at 1:50 dilutions while FITC-goat anti-rabbit IgG was at 1:100 dilution.

Visualization and photography. Slides were viewed on a Zeiss Photomicroscope III with cpifluorescence condenser IIIRS (BG12 blue exciter filter and barrier filter 50). Kodak Tri-X film (ASA 400) was used for all photography. Photographs of fluorescent sections were taken with a 1-min exposure time except where otherwise noted. Printing of all photographs of fluorescent sections was performed identically to allow meaningful comparisons.

After the immunofluorescence had been photographed, coverslips were removed and the sections were stained with Mayer's hematoxylin-eosin or periodic acid Schiff's-hematoxylin for identification of cells (Oakberg, 1956).

\section{RESULTS}

The PGK antisera have previously been characterized by double immunodiffusion and enzyme immunoinac- tivation (Lee et al., 1980). Anti-PGK-2 serum did not cross-react with PGK-1. However, anti-PGK-1 serum (which had not been absorbed on PGK-2) did show cross-reactivity with PGK-2. I have subsequently absorbed the anti-PGK-1 serum on PGK-2 to remove this cross-reactivity (see Materials and Methods).

The following experiments were performed to assess serum specificity at the level of immunofluorescence. Cultured mouse myoblasts, which contain PGK-1 but not PGK-2, were Bouin's fixed and treated for immunoflorescence. When treated with anti-PGK-1 serum all cells showed fluorescence (Fig. 1a). As expected, treatment of myoblasts with anti-PGK-2 serum resulted in no detectable fluorescence (Fig. 2a). The reciprocal experiment could not be performed because I know of no tissue which contains only PGK-2. However, when the anti-PGK-1 serum was passed through a column of Sepharose-bound PGK-2 there was no loss of immunofluorescence (see Fig. 3a). Comparable absorption of anti-PGK-2 serum on Sepharose-bound PGK-2 removed all detectable fluorescence (Fig. 4a). When testes from immature animals (with no PGK-2 detectable by electrophoresis) were examined by immunofluorescence, they were positive with anti-PGK-1 serum but completely negative with anti-PGK-2 serum (data not shown). Finally, normal rabbit serum produced only diffuse background fluorescence similar to that seen when sections were treated with FITC-goat anti-rabbit IgG alone.

The specific fluorescence detected when testis sections are treated with anti-PGK-1 is depicted in Fig. 3a and the PAS-hematoxylin stain of the same tubule is shown in Fig. 3b. This picture (Fig. 3a) was taken with a 2-min exposure (twice that for the anti-PGK-2 pictures) in order to demonstrate the weak fluorescence for PGK1. The longer exposure results in somewhat greater background fluorescence. Specific fluorescence is localized in interstitial cells and along the outer edge of the tubule. The pattern of fluorescence along the edge of the tubule suggests localization in Sertoli cells. The "flares" of fluorescence that extend from the outer edge of the tubule toward the lumen are extended trunks of Sertoli cell cytoplasm. Spermatogonia along the outer edge of the tubule variably exhibit weak fluorescence but there is no specific staining of any other germinal cells with anti-PGK-1.

Figure 5a shows the pattern of specific fluorescence in a testis section treated with anti-PGK-2 serum. The same field after hematoxylin-eosin staining is depicted in Fig. 5b. No fluorescence is detectable in interstitial cells or along the outer cell layers of the tubule. The fluorescence is completely localized to the innermost layer of cells, which are Stage 14 spermatids. The layer 

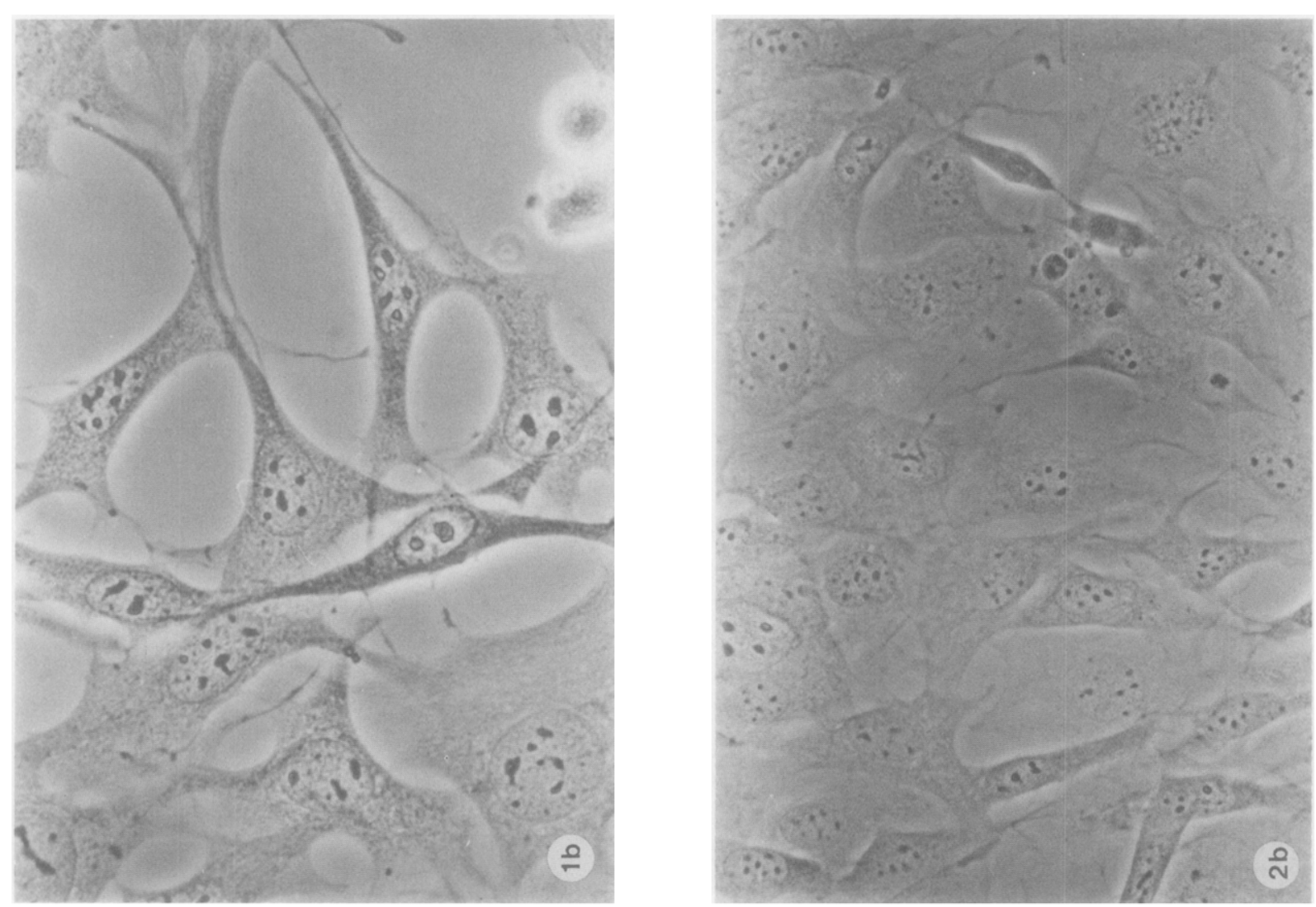

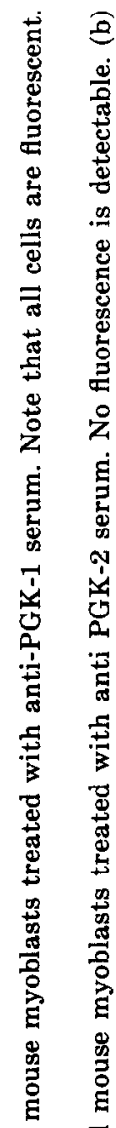

एँ
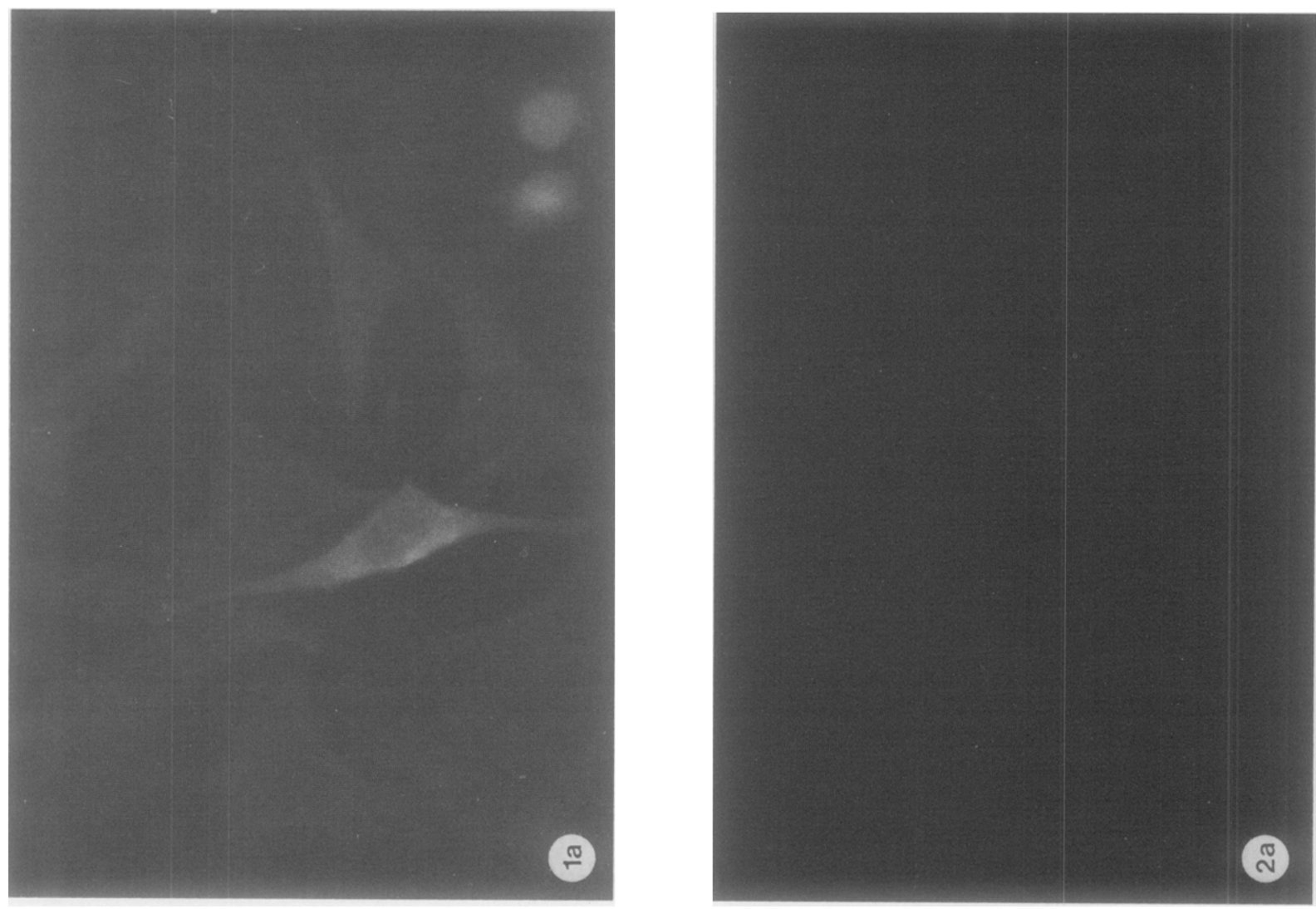

节槖

वृ. ट्रे

mo

氙

ส

案

竞 $\dot{x}$

要品

도.

I.

盟

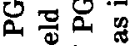

낭 岸

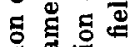

㻤

证

过客

氙密焉

政

要

퉁 경.음

릴

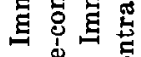

要

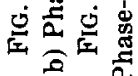



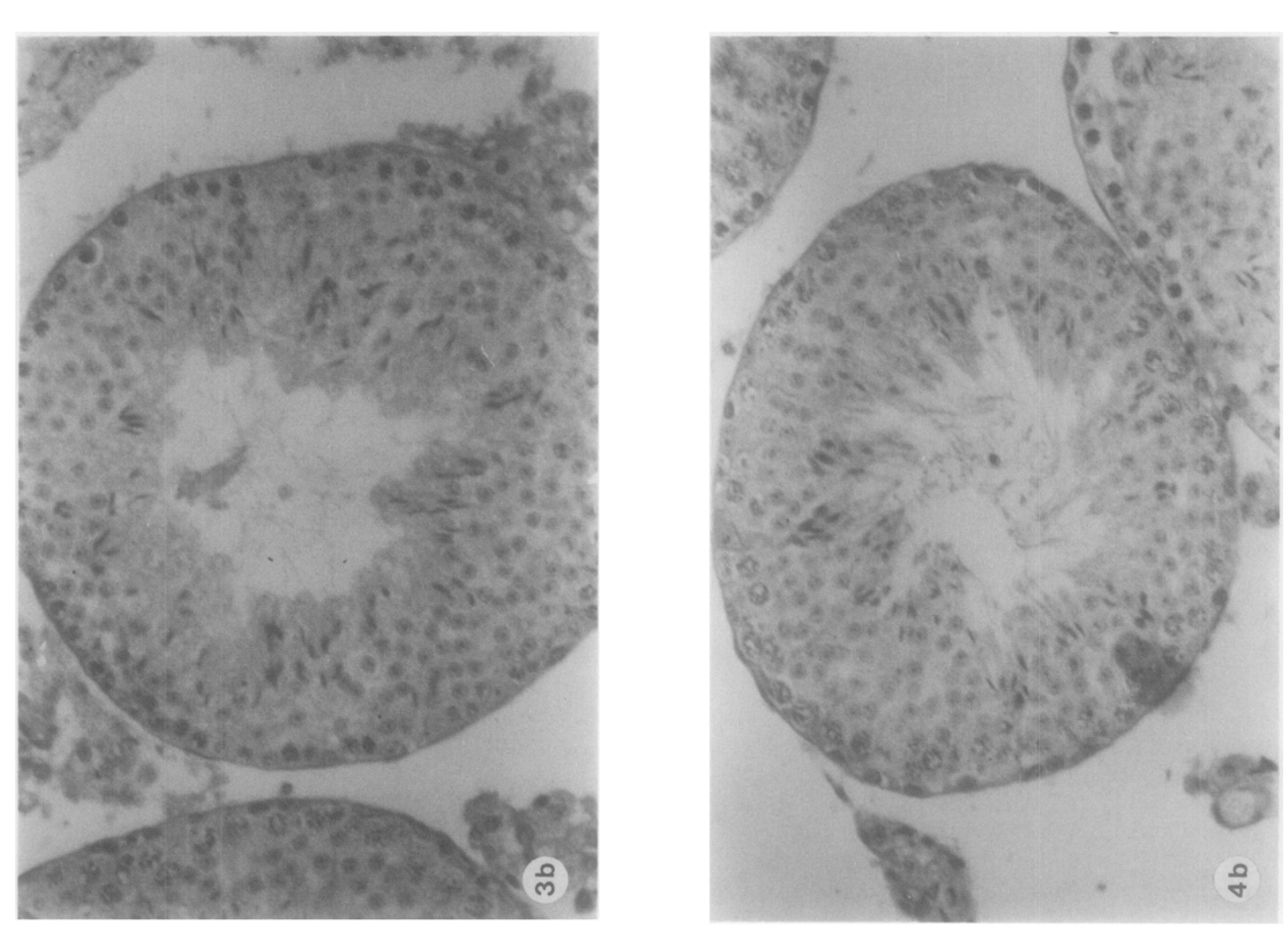

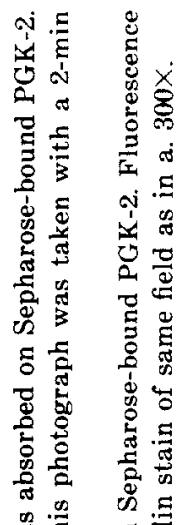

象

总焉

: ने

焉语岂

可路

为

要

気

声㐘

उ

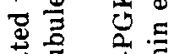

ङ

F告

ङ苛营

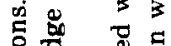
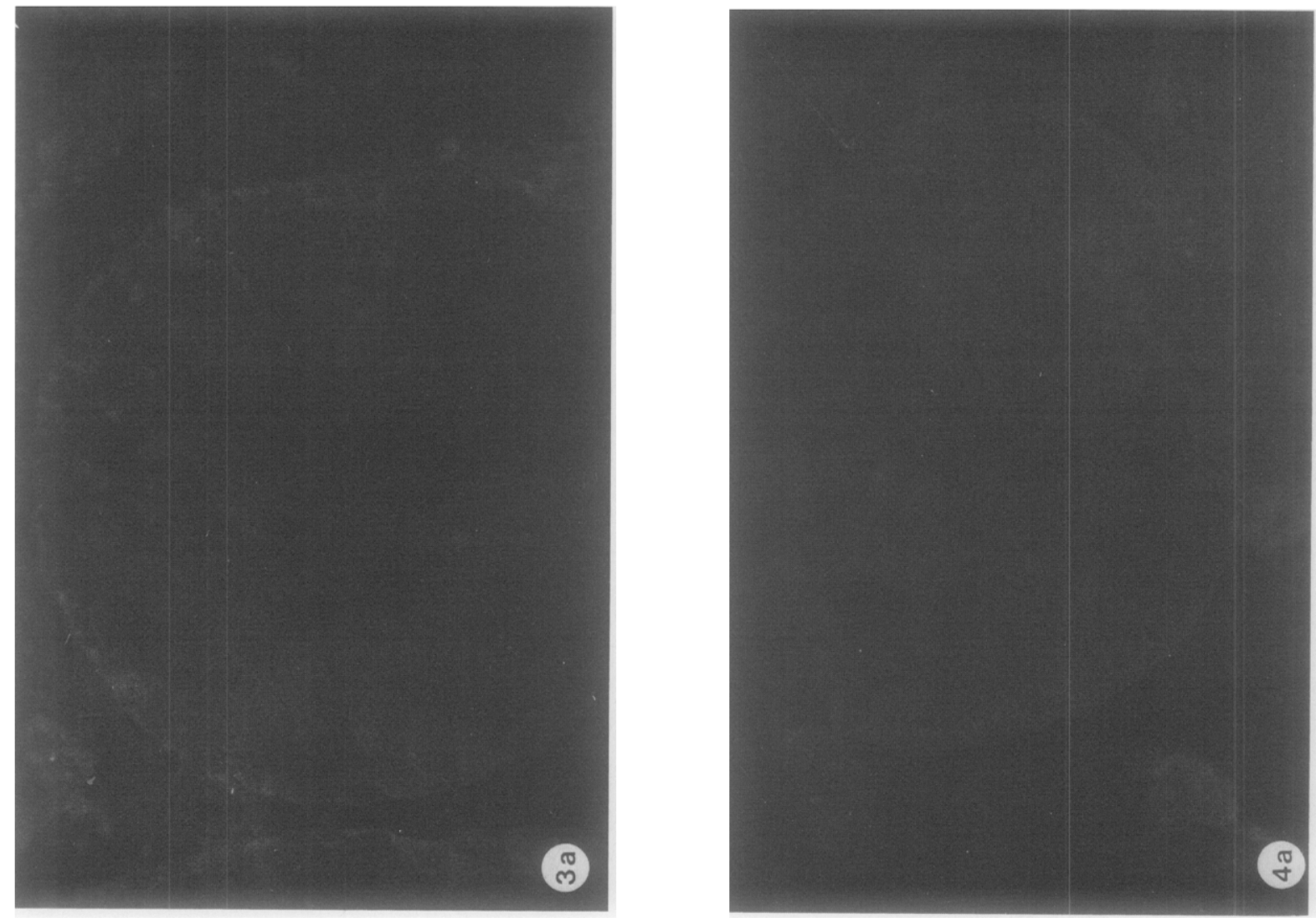

过焉

娄

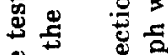

量

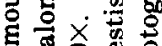

\%

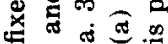

$\infty \cong$ 我

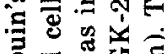

คํำ

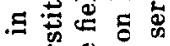

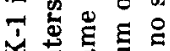

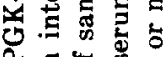

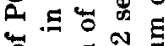

웡

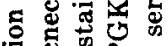

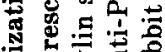

สี

응

पू

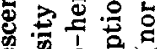

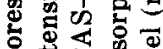

욜

둥

政

药

कि

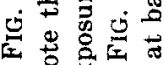


of cells just outside these are Stage 3 spermatids, which exhibit no fluorescence. The intense fluorescence at the extreme right of the picture is localized to Stage 16 spermatids in an adjacent tubule. This tubule also contains Stage 7 spermatids which are not fluorescent. The increased intensity of fluorescence in Stage 16 as compared to Stage 14 spermatids is consistently seen.

Another testis section treated for immunofluorescence with anti-PGK-2 serum is shown in Fig. $6 a$ and the hematoxylin-eosin stain of that section in Fig. $6 \mathrm{~b}$. This tubule contains late Stage 16 spermatids, along the top edge of the lumen, that are about to be released into the lumen. Along the bottom edge of the lumen are dark-staining residual bodies which are the cytoplasmic remnants left behind when the spermatids are released into the lumen of the tubule. Underlying these is a layer of Stage 8 spermatids. The Stage 16 spermatids and the residual bodies show strong fluorescence for PGK-2 while the Stage 8 spermatids are negative as are all other cells in the section.

A large number of immunofluorescent sections from two different animals were examined with the following summarized results. Specific fluorescence for PGK-2 is first faintly detectable in Stage 12 spermatids and increases in intensity through Stage 16 spermatids. At the time of release into the tubule lumen both the mature spermatids and their residual bodies exhibit strong fluorescence for PGK-2. No PGK-2 specific fluorescence is detectable in interstitial cells, Sertoli cells, spermatogonia, spermatocytes, or spermatids prior to Stage 12. Specific fluorescence for PGK-1 is consistently detectable only in interstitial and Sertoli cells. Judging from the intensity of fluorescence the concentration of PGK-2 is much higher than is PGK-1.

\section{DISCUSSION}

It was previously demonstrated by VandeBerg et al. $(1973,1976)$ that activity of the autosomal form of phosphoglycerate kinase (PGK-2) is restricted to the testes and sperm of mice. This suggests that the Pgk-2 locus is one of many loci specifically activated during the differentiative process of spermatogenesis. We have localized PGK-2 in the testis by means of immunofluorescence and shown that it is present only in postmeiotic spermatogenic cells. More precisely, PGK-2 is first detectable in late-middle stage spermatids and appears to increase in concentration as the cells progress to mature late stage spermatids. Conversely, the ubiquitous, X-linked form (PGK-1) appears to be specifically concentrated in nongerminal cells, the interstitial and Sertoli cells.
VandeBerg et al. (1976) were first able to detect PGK2 activity by starch gel electrophoresis in testes of 22 day-old mice, corresponding to the first appearance of early spermatids in the testis. PGK-2 activity was difficult to detect until the age of 30 days at which time a rapid increase in PGK-2 activity was initiated. This corresponds to the first appearance of late-middle stage spermatids in th testis. We have confirmed and extended these findings (Kramer and Erickson, 1981). Using the method of immunofluorescence we could not detect PGK-2 in early spermatids as would be expected from the findings mentioned above. However, our first detection of PGK-2 in late-middle stage spermatids corresponds to the large activity increase which begins in 30-day-old testes. It therefore seems likely that early spermatids have a concentration of PGK-2 which is too low to be detected by immunofluorescence. Subsequently, PGK-2 concentration appears to increase as cells progress from middle to late stage spermatids as is demonstrated by the increasing intensity of fluorescence. This is also the time when double diffusion and enzyme immunoinactivation first revealed the presence of PGK-2 in mouse testes (Erickson et al., 1979).

When sections were treated with anti-PGK-1, only interstitial and Sertoli cells exhibited fluorescence that was consistently above background. This indicates that these cells have relatively high concentrations of PGK1. The failure to detect PGK-1-specific fluorescence in the germ-line cells of the testis suggests that the PGK1 concentration in these cells is low or zero.

Several lines of evidence suggest that the single $X$ chromosome in males is inactivated at meiosis during spermatogenesis (Lifschytz and Lindsley, 1974; Kofman-Alfaro and Chandley, 1970; Monesi, 1965). If this were the case, then transcription of the $P g k-1$ locus would cease at meiosis and the amount of PGK-1 enzyme would be expected to decline as cells progressed through later stages of spermatogenesis. Unfortunately, the sensitivity of our immunofluorescence technique was insufficient to determine if such a decline in PGK-1 occurs.

Two other testis-specific proteins, cytochrome $c_{\mathrm{t}}$ and lactate dehydrogenase- $\mathrm{X}$ ( $\mathrm{LDH}-\mathrm{X})$, have been localized in the testis by immunofluorescence (Goldberg et al., 1977; Hintz and Goldberg, 1977; Wheat et al., 1977) and the earliest appearance of LDH-X activity has also been determined (Goldberg and Hawtrey, 1967). These studies indicate that both cytochrome $c_{\mathrm{t}}$ and LDH-X first appear in midpachytene primary spermatocytes, suggesting that these loci may be coordinately activated (Wheat et al., 1977). The first enzymatic appearance (VandeBerg et al., 1976; Kramer and Erickson, 1981) of PGK-2 and the immunofluorescent localization (pre- 

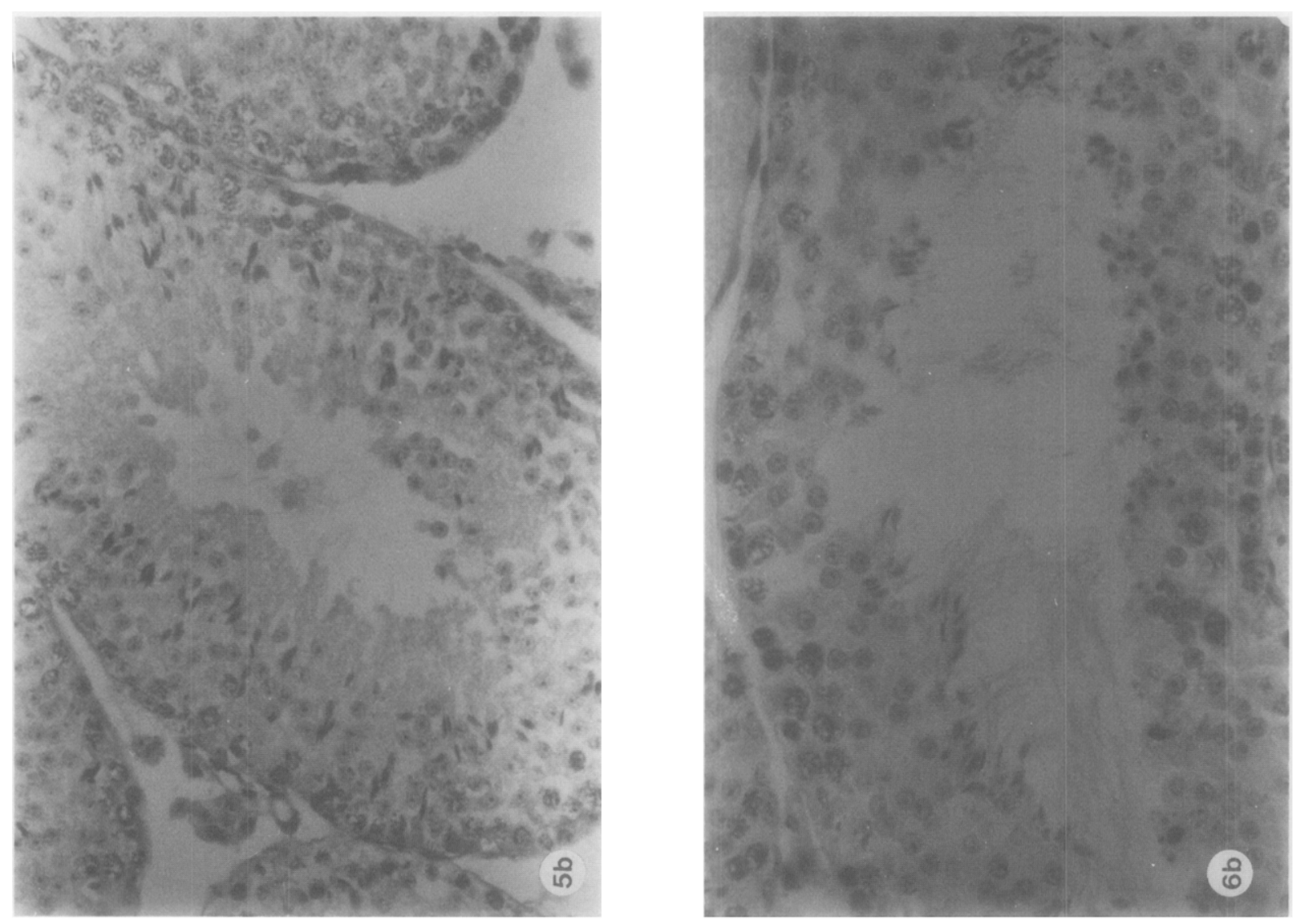

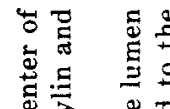

这

s 융

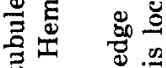

용

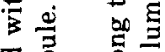

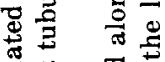

若 吾台

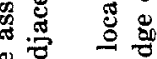

8

ฐ

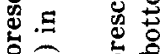

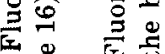

ह

迸

की

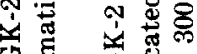

ठ ठ

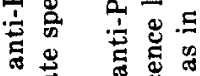

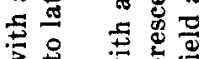

용

要 可

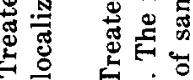

ब.

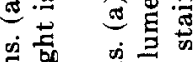

递要

要

㦴

क $\$$

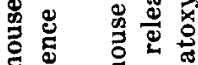

政

항

का

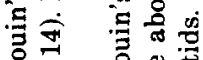

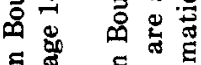

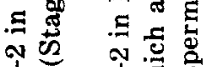

तै

吾

पै है

ह 잉

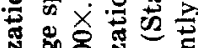

Nof

తู

柾 $\Xi$

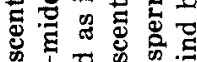

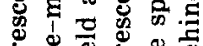

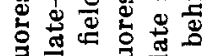

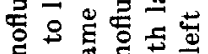

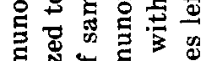

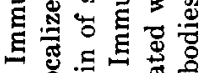

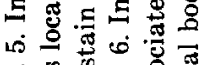


sented in this paper) indicate that PGK-2 appears at a later stage of spermatogenesis, in early spermatids. This makes it unlikely that the Pgk- 2 locus is activated in conjunction with the loci for cytochrome $c_{t}$ and LDH-X.

The great increase in PGK-2 which begins in latemiddle stage spermatids is of particular interest because little or no poly(A) RNA synthesis is detectable in these cells (Geremia et al., 1978; Erickson et al., 1980). Studies on the appearance of the PGK-2 mRNA and the synthesis of the PGK-2 enzyme in different stages of spermatogenesis may elucidate how the expression of this isozyme is controlled. In the accompanying paper, we describe the rates of synthesis for both the PGK-1 and the PGK-2 enzymes during the differentiative progression of spermatogenesis.

The author is grateful to Drs. Tom Connelly and Bob Lloyd for assistance with histological preparations and to Mrs. Rena Jones for excellent secretarial assistance. This work was supported by Genetic Training Grant GM 7544 and Research Grant HD 11738 to R. P. Erickson. This work was submitted in partial fulfillment of the requirements for the Doctor of Philosophy degree in the Horace $\mathrm{H}$. Rackham School of Graduate Studies at the University of Michigan.

\section{REFERENCES}

Chen, S. -H., Donahue, R. P., and ScotT, C. R. (1976). Characterization of phosphoglycerate kinase from human spermatozoa. Fert. Steril. 27, 699-701.

ChEN, S. -H., MALCOLm, L. A., YoshidA, A., and GiBleTt, E. R. (1971) Phosphoglycerate kinase: An X-linked polymorphism in man. Amer. J. Hum. Genet. 23, 87-91.

Cooper, D. W., VandeBerg, J. L., Sharman, G. B., and Poole, W. E. (1971). Phosphoglycerate kinase polymorphism in kangaroos provides further evidence for paternal X-inactivation. Nature New Biol. 230, 155-157.

EiCHER, E. M., CHERRY, M., and FlAHERTY, L. (1978). Autosomal phosphoglycerate kinase linked to mouse major histocompatibility complex. Mol. Gen. Genet. 158, 225-228.

ERICKson, R. P., ERICKSON, J., BETLACH, C. J., and Meistrich, M. L. (1980). Further evidence for haploid gene expression during spermatogenesis: Heterogeneous, poly(A)-containing RNA is synthesized post-meiotically. J. Exp. Zool, 214, 13-19.

Erickson, R. P., Harper, K., Menge, A., and Lee, C. -Y. (1979). Immunological studies of the sperm-specific phosphoglycerate kinase-2 of mice. J. Reprod. Immunol. 1, 185-191.

Geremia, R., D'Agostino, A., and Monesi, V. (1978). Biochemical evidence of haploid gene activity in spermatogenesis of the mouse. Exp. Cell Res. 111, 23-30.
GoldBERG, E., and HAWTREY, C. (1967). The ontogeny of sperm specific lactate dehydrogenase in mice. J. Exp. Zool. 164, 309-316.

GoldberG, E., SBERna, D., WhEAT, T. E., URBANSKI, G. J., and MARGOLIASH, E. (1977). Cytochrome $c$ : Immunofluorescent localization of the testis-specific form. Science 196, 1010-1012.

HINTZ, M., and GoLDBERG, E. (1977). Immunohistochemical localization of LDH-X during spermatogenesis in mouse testes. Develop. Biol. 57, 375-384.

Kofman-Alfaro, S., and Chandley, A. C. (1970). Meiosis in the male mouse: An autoradiographic investigation. Chromosoma 31, 404420.

KozaK, L. A., McLean, G. K., and EichFr, F. M. (1973). X-Linkage of phosphoglycerate kinase in the mouse. Biochem. Genet. 11, 4147.

KrAMER, J. M., and ERICKSON, R. P. (1981). Developmental program of PGK-1 and PGK-2 isozymes in spermatogenic cells of the mouse: Specific activitics and rates of synthesis. Develop. Biol. 87, 37-45.

LeE, C. -Y., Niesel, D., Pegoraro, B., and Erickson, R. P. (1980). Immunological and structural relatedness of isozymes and genetic variants of 3-phosphoglycerate kinase from the mouse. J. Biol. Chem. 255, 2590-2595.

LirSCHY'T, E., and LINDSLEY, D. L. (1974). Sex chromosome activation during spermatogenesis. Genetics 78, 323-331.

Meera Khan, P., Westerveld, A., Grzeschik, K. H., Deys, B. F., GARSON, O. M., and SinisCalCo, M. (1971). X-Linkage of human phosphoglycerate kinase confirmed in man-mouse and man-Chinese hamster somatic cell hybrids. Amer. J. Hum. Genet. 23, 614-623.

MONESI, V. (1965). Differential rate of ribonucleic acid synthesis in the autosomes and sex chromosomes during male meiosis in the mouse. Chromosoma 17, 11-21.

NielsEN, J. T., and CHAPMAN, V. M. (1977). Electrophoretic variation for sex-linked phosphoglycerate kinase (PGK-1) in the mouse. Genetics 87, 319-325.

OAKBERG, E. F. (1956). A description of spermiogenesis in the mouse and its use in analysis of the cycle of the seminiferous epithelium and germ cell rencwal. Amer. J. Anat. 99, 391-413.

Pegoraro, B., ANSARI, A. A., LeE, C. -Y., and Erickson, R. P. (1978). Immunological relatedness of two isozymes of 3-phosphoglycerate kinase from the mouse. FEBS Lett. 95, 371-374.

VANDEBERG, J. L., COOPER, D. W., and Close. P. J. (1973). Mammalian testis phosphoglycerate kinase. Nature New Biol. 243, 48-50.

VANDEBerg, J. L., COOPER, D. W., and Close, P. J. (1976). Testis specific phosphoglycerate kinase B in mousc. J. Exp. Zool. 198, 231 240.

VandeBerg, J. L., Cooper, D. W., Sharman, G. B., and Poole, W. E. (1980). Somatic expression and autosomal inheritance of phosphoglycerate kinase B in kangaroos. Genetics 95, 413-424.

VANDEBERG, J. L., and KLEIN, J. (1978). Localization of mouse PGK2 gene at the D end of the H-2 complex. J. Exp. Zool. 203, 319-324.

Wiieat, T. E., Hintz, M., Goldberg, E., and Margoliash, E. (1977). Analyses of stage-specific multiple forms of lactate dehydrogenase and of cytochrome $c$ during spermatogenesis in the mouse. Differentiation 9, 37-41. 